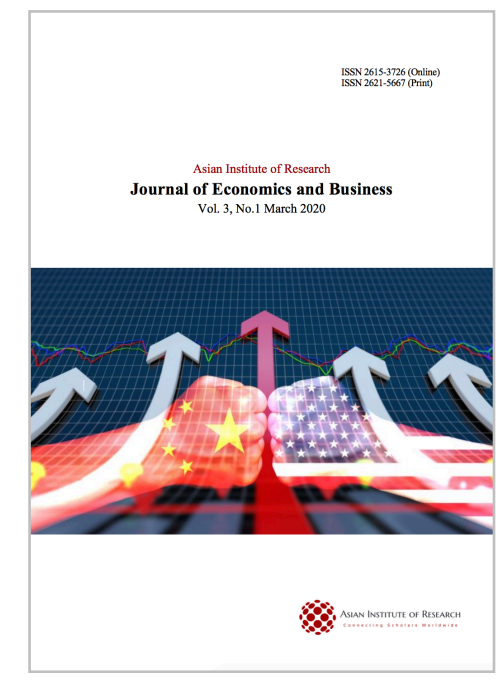

Journal of Economics and Business

Umaru, Ibrahim Gerarh, and Tanko, Abubakar Mohammed. (2020), Economic Valuation of Military Checkpoint-Induced Travel Time Variability in Abuja, Nigeria (2012-2017). In: Journal of Economics and Business, Vol.3, No.1, 29-43.

ISSN 2615-3726

DOI: 10.31014/aior.1992.03.01.176

The online version of this article can be found at: https://www.asianinstituteofresearch.org/

Published by:

The Asian Institute of Research

The Journal of Economics and Business is an Open Access publication. It may be read, copied, and distributed free of charge according to the conditions of the Creative Commons Attribution 4.0 International license.

The Asian Institute of Research Journal of Economics and Business is a peer-reviewed International Journal. The journal covers scholarly articles in the fields of Economics and Business, which includes, but not limited to, Business Economics (Micro and Macro), Finance, Management, Marketing, Business Law, Entrepreneurship, Behavioral and Health Economics, Government Taxation and Regulations, Financial Markets, International Economics, Investment, and Economic Development. As the journal is Open Access, it ensures high visibility and the increase of citations for all research articles published. The Journal of Economics and Business aims to facilitate scholarly work on recent theoretical and practical aspects of Economics and Business. 


\title{
Economic Valuation of Military Checkpoint-Induced Travel Time Variability in Abuja, Nigeria (2012-2017)
}

\author{
Ibrahim Gerarh Umaru¹, Abubakar Mohammed Tanko² \\ ${ }^{1}$ Department of Economics, Kaduna State University, Kaduna-Nigeria \\ ${ }^{2}$ Department of Economics, Nigerian Defence Academy, Kaduna-Nigeria
}

Correspondence: Ibrahim Gerarh Umaru. Email: ibrahim.umaru@kasu.edu.ng

\begin{abstract}
Between 2009 and 2016, Nigeria witnessed insurgency attacks from such militant groups as Movement for the Emancipation of Niger Delta (MEND), Movement for the Actualization of the Sovereign State of Biafra (MASSOB) and O'odua People's Congress (OPC). The most vicious and infamous threat yet was from the selfstyled terrorist group going by the name, Jama'atuahlus-sunnah lid-da'awatiwal Jihad, otherwise known as Boko Haram. The group claimed responsibility for spate of bombings recorded not only within the north-east region of the country but on private and public buildings, bus stations, shopping malls, recreation centres and markets in major cities such as Kaduna, Kano and Abuja, Nigeria. The apparent threat to national security and perhaps most importantly to lives in these cities led security operatives, especially the Military and the Police, to erect checkpoints at strategic locations along major arteries and roads adjudged to be of strategic interest to the terrorists as one of the effective measures to curtail the activity of the terror groups. One of the fallouts of this measure is the phenomenon of obstruction of traffic and delays in reaching travel destinations by commuters often referred to in technical terms as travel time variability. Using the Nolan and Small (1995) modified economic valuation model and the erection of military checkpoints on the three highways in Abuja-Nigeria between 2012 and 2016 as reference points, this study examines the implication of the travel time variability in the federal capital territory (FCT). The findings of the study show that the mounting of military checkpoints might have cost the FCT between N8.25 and N9.58 billion annually within the period. For the period under study (2012 - 2016), the FCT economy might have lost between N40 and N59 billion to obstruction and traffic congestion occasioned by the mounting of military checkpoints.
\end{abstract}

Keywords: Military Checkpoint, FCT Highways, Travel Time, Time Variability, Start Time, Insurgency, Destination

\section{INTRODUCTION}

Since 2009 the Nigerian authorities have been battling the security threat posed by insurgency and terrorist groups Jama'atuahlus-sunnah lid-da'awatiwal jihad, (otherwise known as Boko Haram), Movement for the Emancipation of Niger Delta (MEND), Movement for the Actualization of the Sovereign State of Biafra (MASSOB) and O'odua People's Congress (OPC). The daring and systematic nature of the attacks compelled the implementation of certain counter-terrorism measures. A major strategy deployed by the Nigerian security apparatus was the establishment of military checkpoints along major highways and arterial roads to major cities. These checkpoints were intended 
to assist the military in conducting surveillance using the stop and search system of motorists plying such roads and highways.

In the Federal Capital Territory, Abuja military checkpoints were mounted on the three major highways, namely, Nyanya-Keffi motorway, Murtala Mohammed (Kubwa-Zuba) expressway and Umar Musa Yar'adua (Airport Road) motorway. In spite of the intended benefit of mounting the military checkpoints in terms safety and physical security of road users, commuters may probably have found those checkpoints most inconveniencing because of the physical exhaustion, delays in arrival time to destination and additional economic costs that were often associated with them on a daily basis. What is more, when translated in monetary terms, all this may have had serious repercussions for the economy, especially for the period these checkpoints were enforced. Herein lies the rationale for studying the phenomenon of traffic congestion and the associated problem of travel time variability in the FCT.

The remainder of the paper is organized in three parts. The fourth part interprets the results. The third section outlines the methodology adopted for the study. The next section clarifies key concepts and reviews of extant literature. It also attempts to bring out the gaps in the literature. The last section forms the concluding part of the discourse.

\section{LITERATURE REVIEW}

Travel time can simply be defined as the expected time duration in which a commuter travels from one point to another. Commuter travel time could vary with respect to the schedule a commuter leaves home for office, business or leisure. A commuter has the possibility of departing on an early or late schedule. Biliyamin and Abosede (2012) define travel time variability in terms of how travel times vary over time (e.g., hour-to-hour, day-to-day, week-toweek). In general, travel time variability is the variability of scheduled travel time of a commuter from his/her departure to arrival point over the period of existence of established military checkpoints.

A number of factors are often responsible for the discrepancy between scheduled arrival and actual arrival times. One such factor is traffic congestion. Traffic congestion is defined as a condition on transport networks that occurs as use increases and is characterized by slower speeds, higher trip times and increased vehicular queuing (McKnight, Levison, Ozkay, Kamga and Paaswell, 2004). This is particularly typical with the physical use of roads by vehicles. Travel congestion or delay or jam can make trip times longer, and increases are queuing. Congestion may result from a decrease in capacity, accidents on the roads being closed, or delay or jam or even checkpoints mounted. What is critical about traffic congestion is that it imposes a substantial operational and monetary penalty on-road transportation by increasing the time required to provide service and commute from one point to another (McKnight, Levison, Ozkay, Kamga and Paaswell, 2004). In most heavily built-up cities, heavy traffic congestion is an everyday occurrence but largely as happenstance. It could, however, be the outcome of a deliberate action by the relevant security authorities to either forestall or counter an imminent breach of public peace or even restore tranquility to a troubled or war-torn area within their sphere of control. Such action could come in form of a police or military checkpoint.

A military checkpoint is a strategic position stationed on a road or pathway characterized by obstructive objects used to slow down or stop the movement of people and/or vehicles (FMI, 2004). Such checkpoints provide many advantages, including the ability to control how people enter the town/city so that security personnel can screen entrants to identify troublemakers (be they criminals, terrorists or simple rabble-rousers) and locate contraband items or lethal weapons such as improvised explosive devices (IEDs) (FMI, 2004).

The main impetus for time allocation and travel time variability draws its rationale from time allocation theory and theory of Consumer behavior. Travel behaviour and valuation of travel time have been explored for more than thirty (30) years by researchers from different perspectives. The theories of time allocation deal with the issue of time valuation. Many concepts of value of time emerge, depending on how a period of time is looked at; as a valuable resource, as something to be reassigned or as something to be reduced. Most researchers of this subject apply Consumer Behavior theory to develop models and explain the valuation of travel time savings. 
Consumer theory models individual behavior as if what the individual does (consume) is governed by the search for satisfaction, which in turn is governed by his income. Becker (1965) had postulated the idea of 'final goods' as those which directly induce satisfaction. He paid attention to market goods and entered utility and time as a necessary input to prepare final goods. His main idea was that work time was, in fact, total time in a period minus preparation-consumption time. Johnson (1966) establishes that the reason behind a value of travel time equal to the wage rate was the absence of work time in the utility function. He shows that correcting this omission led to a value of time equal to the wage rate plus the subjective value of work (ratio between the marginal utility of work and the marginal utility of income). Johnson (1966) claims that this was the value of leisure, which in turn was equal to the value of travel time.

Oort (1969) suggests that travel time should be included in utility as well, and a third term appeared in the subjective value of travel time notion; namely, the value of the direct perception of travel time in utility. This is also intuitively attractive, as an exogenous reduction in travel time itself, which might make it even more attractive if travel is pleasurable in itself. De Serpa (1971) makes a significant input to the discussion of the value of time by introducing explicitly a set of technical constraints relating time and good. He postulates a utility function dependent on all goods and all time periods (which he called "activities"), including work and travel. He outlines two different concepts of time value within this framework. First is the value of time as a resource, which is the value of extending the time period, equivalent to the ratio between the marginal utility of (total) time and the marginal utility of income. The second is the value of time allocated to a certain activity (value of time as a commodity), given by the rate of substitution between that activity and money if the individual assigns more time to an activity than the minimum required.

The first to formulate a model for consumer behaviour in which utility depended only on time assigned to activities was Evans (1972). He criticizes Johnsons (1966) work because of the confusion between value of time and value of leisure. He also questions Oort (1969) who compared a reduction in travel time with an extension of the day. Finally Evans (1972) finds the possibility of a zero value for the marginal utility of income for individuals that earn money faster than their capability to spend it; thus, their time constraint is binding and the income constraint is not, which means an infinite value of time as a resource and an infinite value of saving time. Jara-Diaz (2000) remodels the works of Becker (1965), Johnson (1966), Oort (1969), and De Serpa (1971) and arrives at what he calls the 'subjective value of travel time' (SVTT).

Others present a different concept of value of time that flow from different theories of time allocation and came up with three components of value of saving travel time: the wage rate, the value of work and the value of travel as a commodity, and show what one obtains when the rate of substitution between travel time and travel cost is calculated from a utility function estimated from discrete travel choice models. The model highlights coincidences and differences showing that there has been an evolution towards a better understanding of the elements that determine money equivalencies for the variation in time assigned to activities. From a time value equal to wage rate for all activities, the model develops values that are activity-specific due to the introduction of new important elements in the underlying model for consumer behavior, affecting the arguments of utility and set of constraints.

Another major contribution to the work on travel time shows up in the work of Small (1982). He includes departure time as a variable, which influences utility, travel time and travel cost. The introduction of an institutional constraint that links departure time, working hours, and the wage rate generates a resource value of time that depends on work schedule. Therefore, a reduction in travel time induced by exogenous factors might favor a pleasurable rescheduling of activities. He, therefore, provides a more attractive framework to model the impact of travel time variability on arrival times. This he did by taking into account the consequences of arriving at destination earlier or later than desired and individuals choosing the time at which they depart. In his model, commuters adapt their behaviour to the presence of variable travel times by choosing earlier departure times.

Barely after a decade, Noland and Small (1995) developed a general framework that can be used to analyze total expected cost function of travel time. The basic idea behind this framework is to follow the economizing behaviour of an average commuter and determine the risk of arriving early or late to destination. They argue that essentially a traveler or commuter usually has a certain preferred time for arrival for his/her journey. The goal, therefore, is 
to reach the destination by finding the optimal departure time from the start-point, given the estimations of values of schedule delay early and of schedule delay late. Their framework is so flexible that it explicitly recognizes the fact that travel time variability can assume different distributions in a day and the need to fit empirical data to the right distribution. Since this landmark publication, several attempts have been made to empirically measure travel time variability due to congestion and their associated cost. Such pioneering works include Alcantara de Vasconcellos (2004), Srinivasan and Rogers (2005), De Borger and Fosgerau (2006, 2008), Börjesson, Fosgerau and Algers (2009), Börjesson and Eliasson (2010), Beaud, Blayac and Stephen (2016), Wanjek and Hauger (2017), Buchel and Corman (2018).

Travel time variability research in Nigeria is of recent history. The available studies seem to concentrate mostly on merely estimating travel time variability, with only few of them attempting to identify and analyze the channels through which variability in travel time affects the economy. For instance, Olatunde (2016) carried a study on the impact of traffic congestion on commuters travel time in Lagos state. Its findings showed that the factors identified that influence traffic congestion in Lagos state were monetary cost, commuters scheduled time, road side and onside parking, road side trading, total disregard for traffic regulations by road users and population of cars on the road. Similarly, Bilyamin and Abosede (2012) carry out a study on effects of congestion and travel time variability along Abuja-Keffi corridor in Nigeria. The study found that uncontrolled motorization is one of the major causes of traffic congestion along the outer ring corridor of Abuja due to the absence of adequate mitigation measures.

Another relevant study noteworthy is the Transport Secretariat of the Federal Capital Territory Administration/Nigerian Institute of Transport Technology (FCTA/NITT, 2009) conducted to analyze the vehicular and passenger traffic flow pattern and characteristics generated and attracted to Federal Capital City (FCC) in order to provide vital, up-date and reliable database for transport and traffic policy and planning programmes for FCC. The results of the study reveal that FCC attracts and generates vehicular traffic of 1,334,784 weekly. Out of these, 723,506 representing 54.2 percent are inbound traffic while 611,278 constituting 45.8 percent are outbound traffic; Out of the six entry and exit routes, Nyanya road records the highest vehicular traffic volume of 357,852 . Out of this 54.8 percent are outbound while 45.2 percent are inbound. In terms of passenger traffic, FCC generated and attracted 9,017,712 passenger trips weekly. Out of this, 4,860,942 were inbound while $4,156,770$ were outbound. Analysis of the hourly traffic flow reveals that $7.00 \mathrm{am}$ to $9.00 \mathrm{am}$ could be regarded as the morning peak period, while $8.00 \mathrm{am}$ to $9.00 \mathrm{am}$ with highest traffic flow could be regarded as morning peak hour for both passenger and vehicular traffic. The hours between $4.00 \mathrm{pm}$ and $6.00 \mathrm{pm}$ could be regarded as evening peak period for both passenger and vehicular traffic. However, $4.00 \mathrm{pm}$ to $5.00 \mathrm{pm}$ records the highest passenger trips of 886,025 , which could be regarded as the evening peak hour. The route analysis also reveals that Nyanya road records the highest passenger trips of 2,962,877 followed by Kubwa road with 1,728,781. Mpape road recorded the least passenger trip in the city. A vehicular composition analysis of the city traffic reveals that cars are most dominant means of transportation in Abuja followed by minibuses. Although, commercial motorcycles have been banned in FCC, motorcycle traffic recorded some remarkable traffic volume of 27,447 on Keffi-Nyanya road.

Insightful as these studies might have been to our general understanding of urban transport infrastructure, traffic congestion and travel time, none has attempted to quantify in monetary terms the impact of the recent establishment of military checkpoints on Abuja highways and commuters' travel time as well as its impact on the local economy.

\section{METHODOLOGY}

\section{Model Specification}

This study adopts the Koster, Verhoef and Kroes (2008) approach of estimating expected cost function of travel time. This approach utilizes Noland and Small (1995) general framework which assumes that people make a tradeoff getting to their destination between being late and being early which can be expressed as:

$$
\mathrm{TEC}=\alpha^{*}(T)+\beta^{*}(\mathrm{SDE})+\gamma^{*}(\mathrm{SDL})+\lambda^{*}(D)
$$

where:

$\alpha=$ value of time for a traveller $(V o T)$ 
$\beta=$ value of schedule delay early $(V S D E)$

$\gamma=$ value of schedule delay late $(V S D L)$

$T=$ travel time

$S D E=$ schedule delay early

$S D L=$ schedule delay late

$T E C=$ total expected costs

$D=$ Additional dummy taking a value of one if SDL $>1$, to account for extra cost due to arriving late. The model also assumes that the distribution of travel times is not constant over time. The basic model can be briefly described as follows.

A traveller or commuter usually has a certain preferred time for arrival $(P A T)$ on his/her journey. The goal therefore is to reach the destination by finding the optimal departure time $\left(t_{\mathrm{h}}\right)$ from the start-point, given the estimations of $V S D E$ and VSDL and the travel time distribution. An intuitive feel of this can be likened to a scenario where the traveller decides when he/she wants to arrive at destination, and then decides when he/she would have to leave the start-point given all the 'troubles' to encounter during the trip.

If T denotes travel time, then the traveller is said to be late if $t_{\mathrm{h}}+T\left(t_{\mathrm{h}}, \theta\right)>P A T$, and early if $t_{\mathrm{h}}+T\left(t_{\mathrm{h}}, \theta\right)<P A T$ for a realization of $\mathrm{T}$. The travel time $\mathrm{T}$ depends on the time that a traveller departs the start-point and other factors $\theta$. To calculate the costs, the cost function is split into three parts:

$T E C=E C^{\alpha}+E C^{\beta}+E C^{\gamma}$

where:

$$
E C^{\alpha}=\int_{0}^{\infty} \alpha^{*} T^{*} f(T) d T=\alpha^{*}[E(T)]
$$

which assumes a fixed distribution over time, with $\alpha$ being the value of time for a traveler and $E(T)$ the expectation of the travel time.

$$
\begin{aligned}
E C^{\beta} & =\int_{0}^{P A T-t_{h}} \beta^{*}\left(P A T-T-t_{h}\right) f(T) d T \\
& =\int_{0}^{P A T-t_{h}} \beta^{*}\left(P A T-t_{h}\right) * f(T) d T-\int_{0}^{P A T-t_{h}} \beta^{*} T^{*} f(T) d T \\
& =\beta^{*}\left(\mathrm{PAT}-\mathrm{t}_{\mathrm{h}}\right) * F\left(P A T-t_{h}\right)-\left[\int_{0}^{\infty} \beta^{*} T^{*} f(T) d T-\int_{P A T-t_{h}}^{\infty} \beta^{*} T * f(T) d T\right] \\
& =\beta^{*}\left(\mathrm{PAT}-\mathrm{t}_{\mathrm{h}}\right) * F\left(P A T-t_{h}\right)-\beta^{*}\left[E(T)-\int_{P A T-t_{h}}^{0} T^{*} f(T) d T\right]
\end{aligned}
$$

where the last integral is a part of the expectation since the integral is not starting at 0 , but at $P A T$ - $t_{\mathrm{h}}$. If $t_{h}$ is equal to $P A T$, which means a late departure time from home, the costs for being early tend towards zero because the chance of being early is zero, and the partial expectation is equal to $E(T)$.

$$
\begin{aligned}
E C^{\gamma} & =\int_{\text {PAT- } \mathrm{t}_{\mathrm{h}}}^{\infty} \gamma^{*}\left(T-\left(P A T-t_{h}\right)\right) f(T) d T \\
& =-\int_{P A T-t_{h}}^{\infty} \gamma^{*}\left(P A T-t_{h}\right) * f(T) d T+\int_{P A T-t_{h}}^{\infty} \gamma^{*} T^{*} f(T) d T \\
& =-\gamma^{*}\left(\text { PAT }-\mathrm{t}_{\mathrm{h}}\right) *\left[1-F\left(P A T-t_{h}\right)\right]+\gamma *\left[\int_{P A T-t_{h}}^{\infty} T^{*} f(T) d T\right]
\end{aligned}
$$

The expected costs for being late tend to move in the reverse direction with the costs of being early. That is, if the traveller or commuter departs earlier from home, $t_{\mathrm{h}}$ will be smaller and the chance of being late would be smaller so that the first part of the costs decrease. The costs of being late are maximal if $t_{\mathrm{h}}$ is equal to $P A T$. In that case the integral is equal to the expectation $E(T)$. The optimal departure time can then be calculated using the first derivation of the total expected costs with respect to $t_{\mathrm{h}}$ when setting to zero. Koster, Verhoef and Kroes (2008) have argued that it is not quite safe to assume that travel time is independent of the departure from the start-point. However, 
the closed-form total expected cost functions are really useful for application. In view of this, the travel costs can be computed for every departure time from the start-point, given a certain distribution and a preferred arrival time, and subject to choosing the departure time with the lowest costs.

Commuter time is affected by numerous factors, leading to uncertainty. The stochastic nature of those influencing factors which have been classified by van Oort, Sparing, Brands and Goverde (2015) as either internal or external factors leads to the discrepancy between scheduled and actual time of arrival at destination which is often perceived as unreliability and highly inconveniencing for commuters and other road users. Bates, Polak, Jones and Cook (2001) have found that a reduction in travel time variability is even more valuable to commuters than a reduction in travel time itself. Estimating travel time variability and its economic costs is therefore important for gaining knowledge of the deteriorations and ameliorations in daily traffic and for transport policy. Understanding travel time variability in reality however requires some knowledge of probabilistic distributions as they are capable of describing the nature and pattern of travel time variability. Understanding the distributions of travel time distribution is indeed a vital component for analyzing the cost of unreliability to commuters (Mazloumi, Currie and Rose, 2010; Buchël and Corman, 2018). Three theoretical probabilistic distributions have been suggested for empirically estimating the cost of travel time, namely exponential, Weibull and gamma distribution (Koster, Kroes and Verhoef, 2011). For a brief discussion of these distributions, see the Appendix.

\section{Data and Methods}

This study relied largely on primary data for analysis. Data were collected on the socio-demographics of respondents and information related to their travel routes, travel means, travel time and travel cost. Other specific information sought included those on their routine trips on the three major road arteries in the FCT, namely Umar MusaYar'adua expressway, Nyanya-Keffi expressway and Murtala Mohammed Expressway. As real-time collecting data on the three routes would be too overwhelming, a suitable sampling method of FCT residents was adopted for the study. The official census figures provided by National Bureau of Statistics (NBS, 2009) was used as the sampling frame, while the UNFPA (2014)'s projected population figures for the FCT and Yamane (1964) formula were employed to determine the sample size for the study as shown in Table 1.

Table 1: Sample size determination

\begin{tabular}{|c|c|c|c|c|}
\hline \multirow[t]{2}{*}{ Area council } & \multicolumn{2}{|c|}{2006 Population ${ }^{\prime}$} & \multirow{2}{*}{$\begin{array}{l}2014 \text { Projected } \\
\text { Population } \\
\text { (c) }\end{array}$} & \multirow{2}{*}{$\begin{array}{l}\text { Desired sample } \\
\text { (d) }=\left[\#_{x}(c) / 100\right]\end{array}$} \\
\hline & $\begin{array}{l}\text { Number } \\
\text { (a) }\end{array}$ & $\begin{array}{l}\% \text { of Total } \\
\text { (b) }\end{array}$ & & \\
\hline \multirow{2}{*}{$\begin{array}{l}\text { Abaji } \\
\text { Abuja Municipal }\end{array}$} & 58,642 & 4.17 & $123,349.4$ & 16 \\
\hline & 776,298 & 55.2 & $1,633,762$ & 220 \\
\hline Bwari & 229,274 & 16.3 & 529,565 & 71 \\
\hline Gwagwalada & 158,618 & 11.3 & $333,820.3$ & 43 \\
\hline Kuje & 97,233 & 6.9 & $204,631.9$ & 26 \\
\hline Kwali & 86,174 & 6.1 & $181,357.7$ & 24 \\
\hline Total & $1,406,239$ & 100 & $2,959,507$ & $400^{\#}$ \\
\hline \multicolumn{5}{|l|}{ Note: } \\
\hline$\#-\mathrm{s}=\frac{N}{3+N\left(M E^{2}\right)}$ & $\frac{2,959,507}{3+2,959,507\left(0.05^{2}\right)}$ & & & \\
\hline $\begin{array}{l}\text { Source: } \\
\dagger \text { - NBS (2009) } \\
\neq- \text { Projected basec }\end{array}$ & n NBS (2012) & & & \\
\hline
\end{tabular}

A simple random sampling method and the random number table were used as sampling instruments. Thereafter, a multi-stage sampling procedure was followed to select the sample elements. To select 31 percent of the over 60 districts and major settlements in the FCT in identifying the streets and households to be interviewed, the Yamane (1964) was employed. Furthermore, to identify the appropriate sampling units in each settlement, the latter was 
divided into four cardinal points and the allocated number per settlement was shared equally among the cardinal points. Then a simple random sampling method was used to identify specific households in the selected street to be interviewed. In particular, settlements with organized layouts, especially within the city centre, street numbers and neighbourhood identification were used as additional sampling frames. For unorganized settlements, the Umaru (2013) method of spinning a bottle after each sampling unit was identified and employed. The Statistical Package for Social Science (SPSS) 18 and E-views 9 were used to analyze data collected from the field.

The following eight-step procedure was used to analyze the data collected.

STEP 1: Total costs of travel time for periods before August 2015 and after August 2015 were determined. STEP 2: Having estimated total costs of travel time for before August 2015 and after August 2015, the value of the travel $\mathrm{T}$ was estimated.

STEP 3: To determine if there were differences in travel time before and after 2015, the Chow Test was employed.

STEP 4: Data on other characteristics of commuters was analyzed.

STEP 5: Values of schedule delay early and schedule delay late were determined.

STEP 6: A probability distribution fitting to the observed travel times was undertaken.

STEP 7: The total expected cost in eq. (1), using the distribution of the outcome of Step 6 for every time period was calculated.

STEP 8: The overall total cost of travel time to the local economy was extrapolated based on FCT population and sample estimate of total cost of travel time.

\section{DATA ANALYSIS}

The basic socio-demographic characteristics of respondents are shown in Table 4.1. The table shows that public servants represented 48.3 percent of the total number of respondents while the least was the casual workers recording 3.8 percent. As for their educational attainment, respondents who indicated having completed tertiary education represented 772 percent whereas those with secondary school leaving certificates were a-fifth of the total number. Majority of the respondents were either married or living in a household characterized by extended family relationship. Further analysis of socio-demographics will reveal that majority (54.6 percent) of the respondents indicated they visited the city centre within the study area for work; followed by those on business (34.6 percent) and for leisure (6.4 percent). Respondents who commuted before and after August 2015 were in the majority (52.4 percent).

Further analysis of socio-demographic data from survey showed that about 81 percent of household members commute to city centre on routine basis. Further analysis revealed that the mean travel time for an average commuter was 108.209 minutes, schedule delay early 3.48877 minutes and schedule delay late 44.0083 minutes while the respective standard deviations were 32.9197 minutes, 3.65401 minutes and 23.4772 (Table 1).

Table 1: Socio-demographic statistics of respondents

\begin{tabular}{lccccc}
\hline \multicolumn{7}{c}{ SOCIO-DEMOGRAPHICS } \\
\hline Occupation & Student & Public Servant & Business & Casual $\boldsymbol{W}$. & Contract \\
& 9.2 & 48.3 & 32.8 & 3.8 & 5.9 \\
\hline Education Level & Informal & Primary & Secondary & Tertiary \\
& 0.8 & 7.6 & 19.8 & 71.8 \\
\cline { 2 - 6 } Purpose of Visit & Work & Business & Leisure & Other \\
& 54.5 & 34.6 & 6.4 & 4.6 \\
\hline Currency of Visit & Daily & Weekly & Monthly & \\
& 88.3 & 4.6 & 7.1 & \\
\hline Route & Airport & Kubwa & Nyanya & \\
& 27 & 17 & 56 & \\
\hline
\end{tabular}




\begin{tabular}{|c|c|c|c|c|}
\hline \multirow{3}{*}{$\begin{array}{l}\text { Members of household } \\
\text { who travel to city centre } \\
\text { routinely }\end{array}$} & \multicolumn{4}{|c|}{ Age bracket } \\
\hline & $20-30$ & $31-40$ & 41-50 & $51-60$ \\
\hline & 102 & 324 & 292 & 102 \\
\hline Percentage of & \multicolumn{2}{|c|}{ Before August 2015} & After August 2015 & Both \\
\hline $\begin{array}{l}\text { respondents who used } \\
\text { the route }\end{array}$ & \multicolumn{2}{|c|}{12} & 35.6 & 52.4 \\
\hline \multicolumn{5}{|c|}{ SUMMARY STATISTICS } \\
\hline Statistic & Trave & in minutes & $\begin{array}{l}\text { Schedule delay early } \\
\text { (SDE) in minutes }\end{array}$ & $\begin{array}{l}\text { Schedule delay late } \\
\text { (SDL) in minutes }\end{array}$ \\
\hline Mean & & & 3.48877 & 44.0083 \\
\hline Median & & & 2.67000 & 39.6700 \\
\hline Maximum & & & 21.3300 & 127.220 \\
\hline Minimum & & & 0.00000 & 2.00000 \\
\hline Std. Dev. & & & 3.65401 & 23.4772 \\
\hline Sum Sq. Dev. & & & 5087.024 & 213857.1 \\
\hline Obs. & & & 382 & 389 \\
\hline
\end{tabular}

Source: Author's survey, 2016

Noland and Small (1995) and Koster, Verhoef and Kroes (2007) have argued that the size of the total costs for the traveler depends on the risk probability distribution assumed for the study. So an important question is: which distribution results in the highest costs for the traveler and how much is the difference with the other distribution? Interestingly, this is an empirical matter. In order to determine which among the three optional cost-of-travel-timevariability models to use to analyze the empirical data for the study, the survey data was fit to various distributions - exponential, Weibull and gamma probability distributions) - using the QQ plot. Judging by how close the curve representing the actual curve mimicked the behaviour of empirical curve of the general total cost of travel time, it is easy from Figure 1 that, of three, the Weibull specification [(c) and (d) performed best.

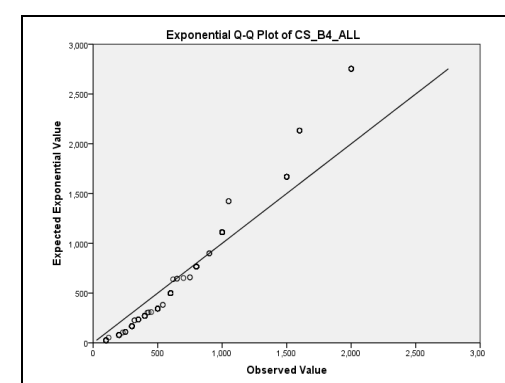

(a)

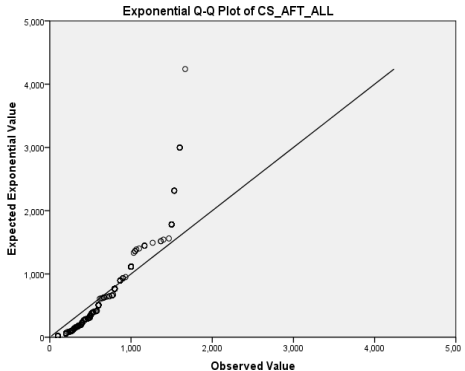

(b)

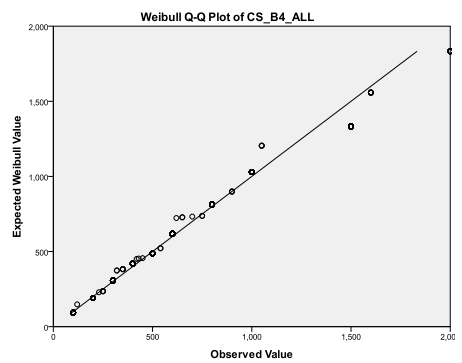

(c)

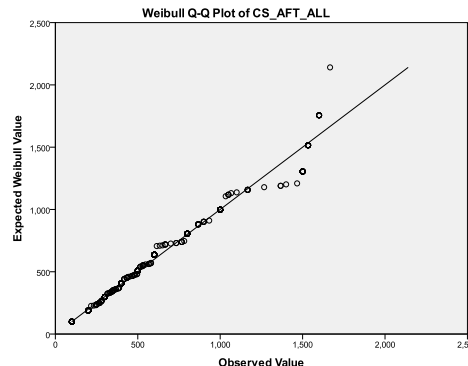

(d)

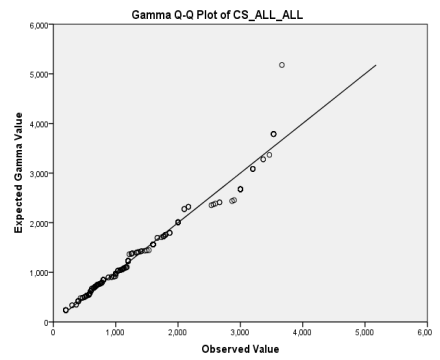

(e)

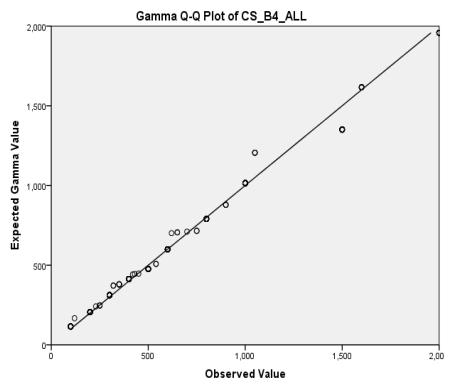

(f)

Figure 1: Distribution fitting (Exponential, Weibull and Gamma) for Travel time survey of FCT, 2015

Source: Author's survey analysis using SPSS Version 18 
To determine the differentials in commuters' travel time and associated costs, the 'general' travel cost equation was estimated for 'before 2015', 'after 2015' and pooled time periods. The results are summarized in Table 2. The table shows that eight out of the twelve estimated coefficients had expected signs. Also, nine out of twelve regression coefficients were significant at 5 percent level. Other associated statistics vital for the Chow Test such as r-squared errors $\left(\mathrm{R}^{2}\right)$ and residual sum of squared errors (RSS) are shown in the lower part of the table.

Table 2: Results of the regression analysis

\begin{tabular}{|c|c|c|c|c|c|c|c|c|}
\hline \multirow[t]{2}{*}{ Variable } & \multicolumn{4}{|c|}{ Before August 2015} & \multicolumn{4}{|c|}{ After August 2015} \\
\hline & Coef. & $\begin{array}{c}\text { Std. } \\
\text { Error }\end{array}$ & t-stat & Prob. & Coef. & $\begin{array}{c}\text { Std. } \\
\text { Error }\end{array}$ & $t$-stat & Prob. \\
\hline Travel time & 5.539 & 0.744 & 7.439 & 0.000 & 4.082 & 1.751 & 2.330 & 0.020 \\
\hline$S D E$ & 33.037 & 9.225 & 3.581 & 0.004 & 53.068 & 9.238 & 5.744 & 0.000 \\
\hline$S D L$ & -1.893 & 2.569 & -0.736 & 0.462 & 0.516 & 1.124 & 0.458 & 0.647 \\
\hline Dummy & 375.97 & 78.728 & 4.775 & 0.000 & 489.59 & 78.75 & 6.216 & 0.000 \\
\hline$R^{2}$ & 0.002 & & & & -0.0047 & & & \\
\hline Ad. $R^{2}$ & -0.005 & & & & -0.056 & & & \\
\hline S.E. Reg. & 455.53 & & & & 406.44 & & & \\
\hline$R S S$ & $79,890,964$ & & & & $62,445,216$ & & & \\
\hline D-Watson & 2.853 & & & & 2.763 & & & \\
\hline \multirow[t]{2}{*}{ Variable } & \multicolumn{4}{|c|}{ Pooled (Before and After) } & & & & \\
\hline & Coef. & $\begin{array}{c}\text { Std. } \\
\text { Error }\end{array}$ & t-stat. & Prob. & & & & \\
\hline Travel time & 2.146 & 1.546 & 7.856 & 0.000 & & & & \\
\hline$S D E$ & -16.979 & 3.394 & -5.001 & 0.000 & & & & \\
\hline$S D L$ & 980.66 & 325.8 & 3.010 & 0.000 & & & & \\
\hline Dummy & -164.76 & 183.2 & -0.899 & 0.369 & & & & \\
\hline$R^{2}$ & 0.061 & & & & & & & \\
\hline Ad. $R^{2}$ & 0.543 & & & & & & & \\
\hline S.E. Reg. & 817.71 & & & & & & & \\
\hline$R S S$ & $88,432,678$ & & & & & & & \\
\hline D-Watson & 2.609 & & & & & & & \\
\hline
\end{tabular}

Source: Author's survey analysis using SPSS Version 18

Performing the Chow Test which utilized the regression results in Table 1 as input was necessary as it helped to ascertain the feasibility of calculating the total expected costs of travel time in the study area. The results for the Chow are shown in Table 3. The calculated value of the $F$-statistic was 1,781. This was compared with the critical value of 3.32 for 387 and 778 degrees of freedom of $R S S_{R}$ and $R S S_{U R}$ respectively to arrive at the decision to reject the null hypothesis which stated that the military checkpoints on Abuja highways' associated costs travel time has changed between the two periods of study. Put differently, there was strong statistical evidence to suggest that the mounting of military checkpoints on Abuja highways had increased commuter travel time within the period under study. This conclusion seems to have been corroborated by the result of the additional test of equality of estimated variance as suggested by Chow (1960) and Gujarati and Porter (2009). Indeed, the value of the calculated Fstatistic for differences in estimated variance was approximately 12.8 , which is greater than its critical $F$-value (3.32).

Table 3: Chow test results

\begin{tabular}{llcc}
\hline Symbol & Explanation & $\begin{array}{c}\text { Restricted equation } \\
\text { (R) }\end{array}$ & $\begin{array}{c}\text { Unrestricted } \\
\text { Equation (UR) }\end{array}$ \\
\hline$R S S$ & Residual sum of squared errors & $256,000,000$ & $274,233,618$ \\
$n$ & Sample size & 393 & 986
\end{tabular}




\begin{tabular}{llcc}
$K$ & Number of parameters & 4 & 4 \\
$d f$ & Degrees of freedom & 389 & 778 \\
\hline$F-C c$ & Chow's $F$-calculated & $1,780.9$ & 3.32 \\
$F-C_{T}$ & $F$-tabulated & $209,324.72$ & \\
$\hat{\sigma}_{1}^{2}$ & Estimated variance of period $(>2015)$ & $15,970.641$ \\
$\hat{\sigma}_{2}^{2}$ & Estimated variance of period $(<2015)$ & 12.793 \\
$F-V_{C}$ & $F$-calculated for differences in estimated & & \\
& variances & & \\
\hline
\end{tabular}

Source: Author's survey analysis using SPSS Version 18

The Weibull and Gama risk distribution versions of eq. (3) were used to calculate the implication of total costs of travel time for the FCT. The summary results are reported in Table 4.

Table 4: SPSS 18 summary results of Weibull distribution estimation costs of travel time for an individual per trip in FCT Before and After 2012

\begin{tabular}{lcccccc}
\hline Variable & \multicolumn{2}{c}{ Before August 2014 } & \multicolumn{2}{c}{ After August 2014 } & \multicolumn{2}{c}{ Pooled } \\
\hline$T$ & Unstand'd & Stand'd & Unstand'd & Stand'd & Unstand'd & Stand'd \\
$S D E$ & 9.290 & 0.797 & 10.895 & 0.648 & 12.878 & 0.920 \\
$S D L$ & 25.697 & 0.093 & 34.232 & 0.122 & 19.537 & 0.063 \\
$D$ & -11.093 & -0.462 & -12.195 & -0.297 & -15.875 & -0.498 \\
$R^{2}$ & 472.746 & 0.443 & 428.262 & 0.421 & 396.981 & 0.376 \\
$D-W$ & 0.852 & & 0.854 & & 0.859 & \\
\hline
\end{tabular}

Source: Author's survey analysis using SPSS Version 18

Table 5 summarizes the total costs of travel time for households intervened in the survey. It represents the total costs of travel time for the 393 households surveyed in the FCT.

Table 5: Total cost of daily travel time for all the individuals over the survey sample in FCT (Weibull and Gamma distributions)

\begin{tabular}{lccc}
\hline Cost & Before August 2014 & After August 2014 & $\begin{array}{c}\text { Change in Total Cost of } \\
\text { Travel Time }\end{array}$ \\
\hline$E C^{\alpha}$ & 252,693 & $347,479.58$ & $94,786.58$ \\
$E C^{\beta}$ & -594.95 & -779.39 & -184.44 \\
$E C^{\gamma}$ & -266.97 & $-3,755.06$ & $-3,488.09$ \\
$T E C$ & $251,831.07$ & $342,945.14$ & $\mathbf{9 1 , 1 1 4 . 0 5}$ \\
\hline
\end{tabular}

Source: Author's computation based survey data analysis

As shown in Table 6, the projected population of FCT as at 2017 was 3,912,307. The cosmopolitan nature of the FCT characterized by high concentration of residential houses, administrative status of capital city, wholesale and retail outlets as well as the quest to access basic utilities have attracted people from all parts of the country might be some of the variables responsible for the growing population of the FCT. As a matter of fact, the concentration of business activities and the high vehicular traffic levels might have 'conspired' with the mounting of military checkpoints to fuel the incessant reoccurrence of traffic congestion in the city at peak periods.

Table 6: Projected population of FCT by Area Council, 2008 - 2017

\begin{tabular}{lrrrrrrr}
\hline $\begin{array}{l}\text { Area } \\
\text { Council }\end{array}$ & $\mathbf{2 0 1 1}^{*}$ & $\mathbf{2 0 1 2}^{\dagger}$ & $\mathbf{2 0 1 3}^{\dagger}$ & $\mathbf{2 0 1 4}^{\dagger}$ & $\mathbf{2 0 1 5}^{\dagger}$ & $\mathbf{2 0 1 6}$ & $\mathbf{2 0 1 7}$ \\
\hline Abaji & 93,309 & $102,406.6$ & $112,391.3$ & $123,349.4$ & 135,376 & $148,575.2$ & $163,061.2$
\end{tabular}




\begin{tabular}{lrrrrrrr} 
AMAC & $1,235,877$ & $1,356,375$ & $1,488,622$ & $1,633,762$ & $1,793,054$ & $1,967,877$ & $2,159,745$ \\
Bwari & 365,007 & $400,595.2$ & $439,653.2$ & $482,519.4$ & 529565 & $581,197.6$ & $637,864.4$ \\
Gwagwalada & 252,522 & $277,142.9$ & $304,164.3$ & $333,820.3$ & $366,367.8$ & $402,088.7$ & $441,292.3$ \\
Kuje & 154,796 & $169,888.6$ & $186,452.7$ & $204,631.9$ & $224,583.5$ & $246,480.4$ & $270,512.2$ \\
Kwali & 137,190 & 150,566 & $165,246.2$ & $181,357.7$ & $199,040.1$ & $218,446.5$ & 239,745 \\
\hline TOTAL & $2,238,751$ & $2,457,029$ & $2,696,590$ & $2,959,507$ & $3,248,059$ & $3,564,745$ & $3,912,307$ \\
\hline
\end{tabular}

NB: ${ }^{*}$ National Bureau of Statistics, 2012

${ }^{\dagger}$ Projected at 9.75 per cent growth rate used by National Bureau of Statistics (2012) for the period 2012 - 2017.

Results obtained from the survey sample show that, with an average of 4.5 household members commuted to and fro the city centre between 2012 and 2017. Based on the sample survey, about 43.83 percent household members were estimated to have visited the city centre daily within the study period. Given the projected population figures in Table 6 and $\$ 91,114.05$ (US \$253.097) per/week as the net total cost of individuals travel time (Table 5), effort was made extrapolate the expected total costs associated with travel time variability between 2012 and 2017. First the average daily total cost an individual incurred due to travel time variability was determined as $\$ 231.84$ (US\$0.644). Finally, the estimated annual average cost of mounting military check points on the FCT highways for the year 2012 was between $\$ 178$ (US\$0.4944) million and $\$ 2,276$ (US\$6.3222) million. In 2017, it rose to between $\$ 283$ (US\$0.786) million and $\$ 3,624$ (US\$90.6068) million. The total expected cost for the six years under study was $\$ 733.068$ (US\$2.036) billion, meaning that within six years of mounting military checkpoint on three arterial highways, the local economy of FCT might have lost in excess of 700 (US\$1.9) billion.

Table 7: Estimated total expected costs of travel time variability due to military checkpoint in the FCT (20152017)

\begin{tabular}{|c|c|c|c|c|c|c|}
\hline Statistic & 2012 & 2013 & 2014 & 2015 & 2016 & 2017 \\
\hline Projected population of FCT ('000) & $2,457.0$ & $2,696.6$ & $2,959.5$ & $\begin{array}{l}3,248 . \\
1\end{array}$ & $3,564.8$ & $\begin{array}{l}3,912 . \\
3\end{array}$ \\
\hline $\begin{array}{l}\text { Total number of household members who } \\
\text { commuted to city centre ('000) }\end{array}$ & $1,101.5$ & $1,208.9$ & $1,326.8$ & $\begin{array}{l}1,456 . \\
1\end{array}$ & $1,598.1$ & $\begin{array}{l}1,753 . \\
9\end{array}$ \\
\hline $\begin{array}{l}\text { Mean total expected cost of travel time } \\
\text { variability (TEC) in the FCT (\#million) }\end{array}$ & $1,137.3$ & $1,248.2$ & $1,369.9$ & $\begin{array}{l}1,503 \\
5\end{array}$ & $1,650.1$ & $\begin{array}{l}1,811 . \\
0\end{array}$ \\
\hline Lower bound of mean TEC (Amillion) & 177.9 & 195.3 & 214.4 & 235.3 & 258.2 & 283.4 \\
\hline Upper bound of mean TEC (\#million) & $2,275.7$ & $2,497.6$ & $2,741.1$ & $\begin{array}{l}3,008 \\
4\end{array}$ & $3,301.7$ & $\begin{array}{l}3,623 . \\
6\end{array}$ \\
\hline Total monthly TEC (Amillion) & $7,961.4$ & $8,737.6$ & $9,589.6$ & 10,500 & 11,600 & 12,700 \\
\hline Total annual TEC (\#million) & $\begin{array}{l}95,536 . \\
8\end{array}$ & $\begin{array}{l}104,851 \\
2\end{array}$ & $\begin{array}{l}115,075 \\
2\end{array}$ & $\begin{array}{l}126,00 \\
0\end{array}$ & 139,200 & $\begin{array}{l}152,40 \\
0\end{array}$ \\
\hline
\end{tabular}

\section{CONCLUDING REMARKS}

This study shows that the mounting military checkpoints on the FCT highways between 2012 and 2017 may have affected the economy of FCT adversely. For the period under study (2012 - 2017), the FCT economy may have lost over $\$ 730$ billion to traffic congestion occasioned by the mounting of military checkpoint.

Any measure to minimize the significant negative externalities of increased traffic congestion on express motorways in FCT, and indeed Nigeria, must recognize the need to reduce commuters' travel time variability. In view of this, the following are recommended:

a. There is the need to develop and deploy new approach to achieving security checking at checkpoint without unnecessarily creating more traffic congestion by security agencies, especially the military. In this regard, newer and modern surveillance technologies (radars, remote scanners and cameras) should be considered at such checkpoints. Also security and in particular military operatives should be trained in modern surveillance techniques. 
b. Alternative modes of transport should be considered so as to reduce the pressure on the major arteries leading to the city centre, such as intra-city train and/ tram systems.

c. As this and other studies on commuters' travel time have shown, there is the need to integrate such studies in the environmental assessment process associated with road/transport planning and implementation by federal and state transport authorities. Such economic valuation of road/transport projects can serve as early warning systems as well as provide alternative measures in addressing increased traffic congestion whenever there is the need to mount such in the event of security challenges such as the one currently experienced by Nigeria.

\section{References}

Alcantara de Vasconcellos, E. (2005). Urban change, mobility and transport in Sao Paulo: three decades, three cities. Transport Policy, 12(2), p.91-104.

Bates, J., Polak, J., Jones, P. and Cook, A. (2001). The valuation of reliability for personal travel. Transportation Research Part E: Logistics and Transportation Review, 37(2): 191-229.

Beaud, M., Blayac, T. and Stephen, M. (2016). The impact of travel time variability and traveler's risk attitudes on the values of time and reliability. Transport Research Part B, 93:207-224.

Becker, G. (1965). A theory of the allocation of time. The Economic Journal, 75, 493-517.

Biliyamin, I. A. and Abosede, B. A. (2012). Effects of congestion and travel time variability along Abuja-Keffi corridor in Nigeria. Global Journal of Research In Engineering, 12(3-E).

Börjesson, M., and Eliasson, J. (2010). The value of time and external benefits in bicycle cost-benefit analyses. Selected proceedings of the 12th WCTR.

Börjesson, M., Fosgerau, M. and Algers, S. (2009). The income elasticity of the value of travel time is not one number. In European Transport Conference, 2009. Leiden Leeuwenhorst Conference Centre, Netherlands. 2009-10-5 to 2009-10-7.

Buchel, B. and Carman, F. (2018). Modelling probability distributions of public travel time components. $18^{\text {th }}$ Swiss Transport Research Conference Monte Verita/Ascona, May 16-18, 2018.

Chow, G.C. (1960). Tests of equality between sets of coefficients in two linear regressions. Econometrica, 28(3): 591-605.

De Borger, B., and Fosgerau, M. (2006, August). Another test of the theory of reference-dependent preferences: the trade-off between money and time. In: European Transport Conference proceedings.

De Borger, B., and Fosgerau, M. (2008). The trade-off between money and travel time: A test of the theory of reference-dependent preferences. Journal of Urban Economics, 64(1), 101-115.

De Serpa, A. (1971). A theory of the economics of time. The Economic Journal, 81, 828-846.

Evans, A. (1972). On the theory of the valuation of travel time savings. Scottish journal of Political economy, 19:1-17.

FMI (2004). FMI 3-07.22: Counterinsurgency operations. October, 2004 (expires 1 October, 2006). Appendix C. Population and resources control. Available: www.GlobalSecurity.org. Accessed: 14/12/2016.

Gujarati, D.N. and Porter, D.C. (2009). Basic econometrics $5^{\text {th }}$ edition. Boston: McGraw-Hill.

Jara-Díaz, S.R. (2000). “Allocation and valuation of travel time savings.” Handbook in Transport 1(2000): 303319.

Johnson, M. (1966). Travel time and price of leisure. Western economic journal 4:135-145.

Koster, P., Kroes, E., and Verhoef, E. (2008). Valuing the cost of car travel time variability. Working paper, VU University, Amsterdam, September, earlier version presented at the Kuhmo Necter Conference, Amsterdam, 2008

Koster, P., Kroes, E., and Verhoef, E. (2011). Travel time variability and airport accessibility. Transportation Research Part B: Methodological, 45(10), 1545-1559.

Mazloumi, E., Currie, G. and Rose, G. (2010). Using GPS data to gain insight into public transport travel time variability. Journal of Transportation Engineering, 136 (7): 623-631.

McKnight, C.E., Levison, H.S., Ozkay, Kamga, K.C. and Paaswell, R.E. (2004). Impact of traffic congestion on bus travel time in northern New Jersey. Transportation Research Record. Available: www.citeseerx.ist.psu.edu. Access: 30/08/2017.

Federal capital Territory Administration/Nigerian Institute of Transport Technology (FCTA/NITT, 2009). Final report on Abuja traffic and ridership survey. (Unpublished report)

National Bureau of Statistics (NBS, 2012). Annual abstract of statistics. Abuja: National Bureau of Statistics.

Noland, R. B. and K. A. Small (1995). Travel time uncertainty, departure time choice and the cost of morning commutes. Transportation Research Record, 1493, 150-158. 
Olatunde, R.A (2016). Impact of traffic congestion on commuter's travel time in Lagos state. A thesis of the department of economics, Nigerian Defence Academy Kaduna.

Oort, O. (1969). The evaluation of travelling time. Journal of Transport Economics and Policy, 3:279-286.

Small, K. (1982). Scheduling of consumer activities work trip. America Economic Review 72:467-479.

Srinivasan, S., and Rogers, P. (2005). Travel behavior of low-income residents: studying two contrasting locations in the city of Chennai, India. Journal of Transport Geography, 13(3), 265-274.

Tagaris, E. Liao, K.J., Delucia, A.J., Deck, L., Amar, P. and Russell, A.G. (2009). Potential impact of climate change on air pollution-related human health effects. Environmental Science Technology 1, 43(13): 497988.

Umaru, I.G. (2013). Research methodology: Principles and application in social and behavioral science. Jos, Nigeria: Olive de L'Afrique Consult/Eiwa Ventures

van Oort, N., Sparing, D., Brands, T. and Goverde, R.M.P. (2015). Data driven improvements in public transport: The Dutch example. Public Transport, 7(3): 369-389.

Wajek, M. and Hauger, G. (2017). Reliability of travel time: Challenges posed by a multimodal transport participation. IOP Guf. Series: Materials Science and Engineering, 245 (2017).

Yamane, T. (1964). Statistics: An introductory analysis $3^{\text {rd }}$ edition. New York: Harpen and Row Publishing. 


\section{Appendix}

In case of the exponential distribution with mean $p d f=\frac{1}{k} e^{-\left(\frac{T}{k}\right)}$ and standard deviation $\mathrm{k}$ it is possible to evaluate the integrals of $E C^{\alpha}$ and $E C^{\beta}$ :

$$
\begin{aligned}
E C^{\alpha} & =\int_{0}^{\infty} \alpha^{*} T^{*} f(T) d T=\alpha^{*} E(T)=\alpha^{*} k \\
E C^{\beta} & =\int_{0}^{P A T-t_{h}} \beta^{*}\left(P A T-t_{h}\right) f(T) d T=\int \beta^{*}\left(P A T-T-t_{h}\right) *\left[\frac{1}{k} * e^{\left.\left(\frac{-T}{k}\right)\right] d T}\right. \\
& =\beta^{*}\left[\mathrm{k} *\left(-1+\mathrm{e}^{\frac{-\mathrm{PAT}+\mathrm{t}_{\mathrm{h}}}{\mathrm{k}}}\right)+P A T-t_{h}\right] \\
E C^{\gamma} & =\int_{P A T-t_{h}}^{\infty} \gamma^{*}\left(T+t_{h}-P A T\right) f(T) d T \\
& =\gamma^{*} \mathrm{k}^{*} \mathrm{e}^{\frac{-\mathrm{PAT}+\mathrm{t}_{\mathrm{h}}}{k}}
\end{aligned}
$$

and the optimal travel cost determined as:

$$
\begin{aligned}
& \frac{\partial T E C}{\partial t_{h}}=-\beta+(\beta+\gamma) * e^{\frac{-P A T+t_{h}}{k}}=0 \Rightarrow \frac{\beta}{\beta+\gamma}=e^{-\left(\frac{P A T-t_{h}}{k}\right)} \\
& \mathrm{t}_{\mathrm{h}}{ }^{*}=P A T-k * \ln \left[\frac{\beta+\gamma}{\beta}\right] \\
& T E C^{*}=\alpha^{*} k+\beta^{*} k^{*} \ln \left[\frac{\beta+\gamma}{\beta}\right]
\end{aligned}
$$

To estimate travel time with the Weibull distribution, the different parts of the total costs are as follows:

$$
\begin{aligned}
& E C^{\alpha}=\int_{0}^{\infty} \alpha^{*} T^{*} f(T) d T=\alpha *\left[\lambda * \operatorname{Gamma}\left[1+\frac{1}{k}\right]\right] \\
& E C^{\beta}=\beta^{*}\left(P A T-t_{h}\right) * F\left(P A T-t_{h}\right)-\beta^{*}\left\{E(T)-\text { Gamma }\left[1+\frac{1}{k},\left(\frac{P A T-t_{h}}{\lambda}\right)^{k}\right]\right\} \\
& E C^{\gamma}=\gamma^{*}\left(t_{h}-P A T\right) *\left[1-F\left(P A T-t_{h}\right)\right]+\gamma^{*} E(T) * \text { Gamma }\left[1+\frac{1}{k},\left(\frac{P A T-t_{h}}{\lambda}\right)^{k}\right]
\end{aligned}
$$

Setting the first derivative of the total expected costs to zero we obtain the condition:

$$
\begin{aligned}
& \frac{\partial T E C}{\partial t}=e^{-\left(\frac{P A T-t_{h}}{\lambda}\right)^{k}} *\left\{\left[1-e^{\left(\frac{P A T-t_{h}}{\lambda}\right)^{k}}\right] * \beta+\gamma\right\}=0 \\
& t_{h}^{*}=P A T-\lambda *\left(\log \left[\frac{\beta+\gamma}{\beta}\right]\right)^{\frac{1}{k}}
\end{aligned}
$$

Should the empirical distribution to fit empirical travel time data turned out to be gamma distribution, the three parts of the expected total costs function to estimate are:

$$
E C^{\alpha}=\alpha^{*} E(T)=\alpha^{*} k^{*} \theta
$$




$$
\begin{aligned}
E C^{\beta} & =\beta *\left(P A T-t_{h}\right) *\left[1-F\left(P A T-t_{h}\right]-\beta *\left[E(T)-\int_{P A T-t_{h}}^{\infty} f(t) d T\right]\right. \\
& =\beta^{*}\left(\text { PAT }-\mathrm{t}_{\mathrm{h}}\right) *\left[1-F\left(P A T-t_{h}\right)\right]-\beta^{*}\left\{E(T)-\frac{\theta^{*} \text { Gamma }\left[1+k, \frac{P A T-t_{h}}{\theta}\right]}{\text { Gamma }[k]}\right\}
\end{aligned}
$$

where Gamma[a, $b]$ is the incomplete gamma function. The costs for being late are derived:

$$
\left.E C^{\gamma}=\gamma^{*}\left(t_{h}-P A T\right) *\left[1-F\left(P A T-t_{h}\right)\right]\right)+\gamma^{*} \int T^{*} f(T) d T
$$

$\left.\gamma *\left(t_{h}-P A T\right) *\left[1-F\left(P A T-t_{h}\right)\right]\right)+\gamma *\left\{\frac{\theta * \text { Gamma }\left[1+k, \frac{P A T-t_{h}}{\theta}\right]}{\text { Gamma }[k]}\right\}$

If the first derivative is set to zero, the following will result:

$$
\frac{\partial T E C}{\partial t} \frac{\beta}{\gamma+\beta}=\frac{\text { Gamma }\left[k, \frac{P A T-t_{h}}{\theta}\right]}{\text { Gamma }[k]}=Q\left[k, \frac{P A T-t_{h}}{\theta}\right]
$$

The three parts of the total cost function for the Lognormal distribution are:

$$
\begin{aligned}
& E C^{\alpha}=\int \alpha^{*} T^{*} f(T) d T=\alpha *[E(T)]=\alpha *\left[e^{\mu+\frac{\sigma^{2}}{2}}\right] \\
& E C^{\beta}=\beta^{*}\left(P A T-t_{h}\right) * F\left(P A T-t_{h}\right)-\beta^{*} E(T) * E(T) *\left(1-\Theta\left[R\left(P A T-t_{h}\right)\right]\right. \\
& E C^{\gamma}=\gamma^{*}\left(t_{h}-P A T\right) *\left[1-F\left(P A T-t_{h}\right)\right]+\gamma^{*} E(T) * \Theta\left[R\left(P A T-t_{h}\right)\right]
\end{aligned}
$$

where $F($.$) is the cumulative lognormal probability and \mathrm{E}(\mathrm{T})$ the expectation. Setting the first derivative of the total costs function to zero yields the optimal th:

$$
\frac{\partial T E C}{\partial t_{h}}=(\beta+\gamma) *\left[-F(.)+\left(P A T-t_{h}\right) * \frac{\partial F(.)}{\partial t_{h}}+E(T) * \frac{\partial \Theta(.)}{\partial t_{h}}\right]+\gamma=0
$$

so

$$
\left.\frac{\gamma}{\gamma+\beta}=F\left(P A T-t_{h}\right)+\left(P A T-t_{h}\right) * f\left(P A T-t_{h}\right)-E(T) * g\left(P A T-t_{h}\right) *\left[\frac{1}{\sigma\left(P A T-t_{h}\right)}\right]\right)
$$

where $F($.$) is the cumulative distribution of the lognormal in P A T-t_{\mathrm{h}}, f($.$) is the probability of the lognormal in P A T$ $t_{\mathrm{h}}, g($.$) is the standard normal probability evaluated at P A T-t_{\mathrm{h}}$. 